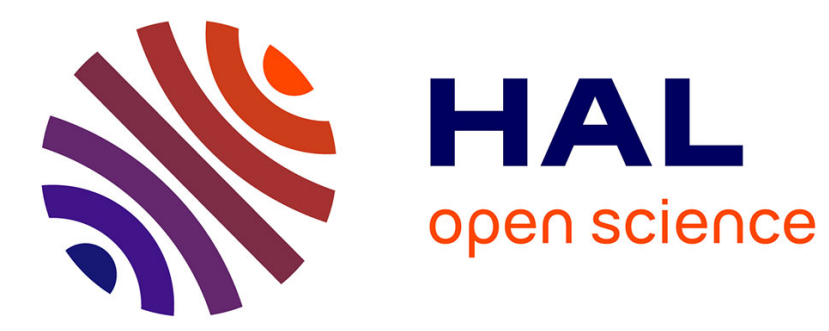

\title{
Suzuki-Miyaura Coupling of (Hetero)Aryl Sulfones: Complementary Reactivity Enables Iterative Polyaryl Synthesis
}

Paul Chatelain, Abhijit Sau, Christopher N. Rowley, Joseph Moran

\section{- To cite this version:}

Paul Chatelain, Abhijit Sau, Christopher N. Rowley, Joseph Moran. Suzuki-Miyaura Coupling of (Hetero)Aryl Sulfones: Complementary Reactivity Enables Iterative Polyaryl Synthesis. Angewandte Chemie International Edition, 2019, 58 (42), pp.14959-14963. 10.1002/anie.201908336 . hal02516516

\author{
HAL Id: hal-02516516 \\ https://hal.science/hal-02516516
}

Submitted on 23 Mar 2020

HAL is a multi-disciplinary open access archive for the deposit and dissemination of scientific research documents, whether they are published or not. The documents may come from teaching and research institutions in France or abroad, or from public or private research centers.
L'archive ouverte pluridisciplinaire HAL, est destinée au dépôt et à la diffusion de documents scientifiques de niveau recherche, publiés ou non, émanant des établissements d'enseignement et de recherche français ou étrangers, des laboratoires publics ou privés. 


\title{
Suzuki-Miyaura Coupling of (Hetero)Aryl Sulfones: Complementary Reactivity Enables Iterative Polyaryl Synthesis
}

\begin{abstract}
Paul Chatelain ${ }^{\mathrm{a}}$, Abhijit Sau ${ }^{\mathrm{a}}$, Christopher N. Rowley ${ }^{\mathrm{b}}$ and Joseph Moran ${ }^{\mathrm{a}}$
Abstract: Ideal organic syntheses involve the rapid construction of $C$ $C$ bonds, with minimal use of functional group interconversions. The Suzuki-Miyaura cross-coupling (SMC) is a powerful way to form biaryl linkages, but the relatively similar reactivity of electrophilic partners makes iterative syntheses involving more than two sequential coupling events difficult to achieve without additional manipulations. Here we develop (hetero)aryl sulfones as electrophilic coupling partners for the SMC reaction, which display an intermediate reactivity between those of typical aryl (pseudo)halides and nitroarenes. The new complementary reactivity allows for rapid sequential crosscoupling of arenes bearing chloride, sulfone and nitro leaving groups, affording non-symmetric ter- and quateraryls in only 2 or 3 steps, respectively. The SMC reactivity of (hetero)aryl sulfones is demonstrated in 30 examples. Mechanistic experiments and DFT calculations are consistent with oxidative addition into the sulfone $C$ $S$ bond as the turnover-limiting step. The further development of electrophilic cross-coupling partners with complementary reactivity may open new possibilities for divergent iterative synthesis starting

expanding the breadth of pseudohalides to include those displaying intermediate reactivity would unlock the complementary reactivity necessary to execute multiple sequential biaryl couplings in a rapid, iterative manner. This is particularly attractive because of the wide potential therapeutic applications of terphenyls. ${ }^{[4],[24],[3],[25]}$ In this regard, SMC reactions of aryl sulfones offer an opportunity to fill this void (Scheme 1a). Aryl sulfones offer a synthetic handle to tune their reactivity, and can direct ortho, meta and para functionalization, ${ }^{[26],[27],[28],[29]}$ while remaining robust to hydrolysis. Sulfones have spiked interest in various cross-coupling reactions, ${ }^{[30],[26],[31]}$ including the benzyl, ${ }^{[32],[33]}$ vinyl[ ${ }^{[34]}$ and tetrazolyl ${ }^{[35]}$ SMC reaction. Surprisingly, a general method for the SMC reaction of aryl sulfones has not appeared. Herein, we describe the discovery and development of the SMC reaction of (hetero)aryl sulfones, which possess an intermediate level of reactivity between aryl chlorides and nitroarenes, thus allowing for rapid access to non-symmetric terand quateraryl compounds via iterative coupling sequences.
\end{abstract} from small pools of polyfunctionalized arenes.

The Suzuki-Miyaura coupling (SMC) reaction is broadly used in academia and industry for the synthesis of bioactive molecules, agrochemicals and organic materials, as exemplified by the 2010 Nobel Prize in chemistry. ${ }^{[1]}$ In biaryl synthesis, by far the most commonly used application of the SMC, the electrophilic partner is typically an aryl halide $(-\mathrm{I},-\mathrm{Br},-\mathrm{Cl})$ or pseudohalide (-OTf). Even with such a well-developed reaction, it can be surprisingly difficult to orchestrate short, iterative sequences of SMC reactions to access non-symmetric ter- and quateraryl compounds because of the relatively small or unpredictable reactivity differences between available electrophilic partners. ${ }^{[2],[3],[4]}$ For example, aryl triflates may react faster or slower than aryl chlorides, depending on the conditions and substrate. ${ }^{[2]}$ Halides and pseudohalides have been used with success for sequential cross-coupling reactions such as in the elegant sequential Negishi couplings by Schoenebeck and coworkers. ${ }^{[5],[6]}$ However, apart from a few exceptions, ${ }^{[2],[4]}$ the synthesis of polyaromatics via sequential SMC reactions remains mostly limited to specific substrates or require iterative functional group manipulations. ${ }^{[7],[8],[9],[10],[11]}$ Efforts have been made to couple new, challenging electrophilic partners, such as a recently developed SMC reaction

However,

P. Chatelain, Dr. A. Sau, Prof. Dr. J. Moran.

University of Strasbourg, CNRS, ISIS UMR 7006,

67000 Strasbourg, France.

E-mail: $\underline{\text { moran@unistra.fr }}$

Prof. Dr. C. N. Rowley

Memorial University of Newfoundland, 283 Prince Philip Drive, St. John's, NL, Canada, A1B 3X7
Scheme 1. Relative reactivity of aryl electrophiles in the Suzuki-Miyaura reaction

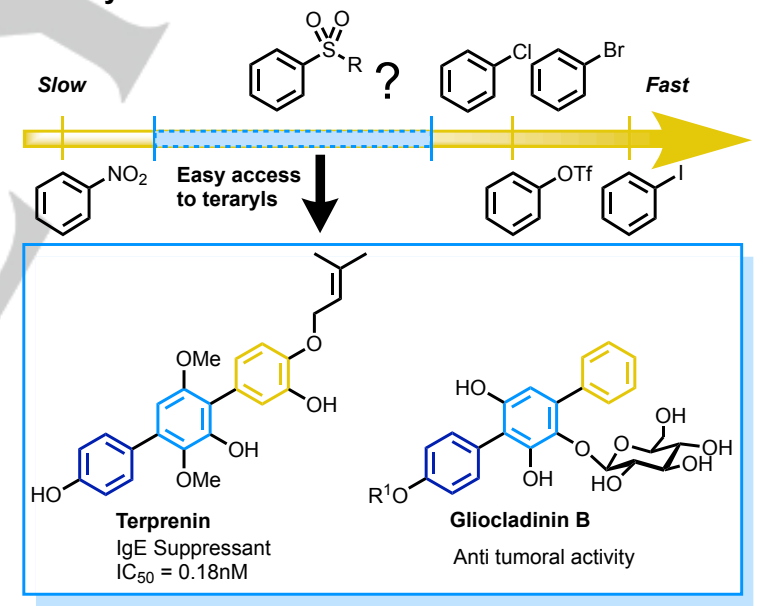

Our initial experiments focused on identifying aryl sulfones capable of acting as electrophilic coupling partners (Table 1). When RuPhos was used as ligand in the presence of $\mathrm{K}_{3} \mathrm{PO}_{4}$, catalytic $\mathrm{Pd}(\mathrm{acac})_{2}$, and a small amount of DMSO, diphenyl sulfone underwent coupling with 4-methoxyphenylboronic acid at $130{ }^{\circ} \mathrm{C}$ (entry 1). Phenyl methyl sulfone and its mono- and difluorinated analogs were not reactive (entry 2-4), but trifluoromethylphenyl sulfone underwent smooth coupling even at $80{ }^{\circ} \mathrm{C}$ (entry 5). The presence of DMSO as additive was found to be important for high yields (entry 6 ). Other additives capable of solubilizing the inorganic base had a similar, though lesser effect (entry 7), whereas water had a detrimental effect (entry 8). Bissulfoxides that could potentially act as ligands were not effective (entry 9). DMSO could not be used as the solvent (entry 10), but the reaction could be carried out efficiently in the absence of DMSO by using micellar water (entry 11). ${ }^{[36],[37]}$ Related functional 
groups, such as trifluoromethyl sulfoxides or trifluoromethyl ketones, did not undergo coupling under these conditions (see Supporting Information). The non-symmetric deactivated di-aryl sulfone 1-(phenylsulfonyl)-3,5-bis(trifluoromethyl)benzene only underwent cross-coupling on the electron-poor arene (entry 12).

Competition experiments comparing aryl sulfones with other electrophiles demonstrated an SMC reactivity at least two orders of magnitude slower than aryl chlorides, but at least two orders faster than nitroarenes and aryl tosylates, under standard conditions (Scheme 2). Interestingly, using XPhos as ligand in place of RuPhos does not enable cross-coupling of sulfones at $80{ }^{\circ} \mathrm{C}$ (Table S1).

\section{Table 1. Evaluation of reaction parameters}

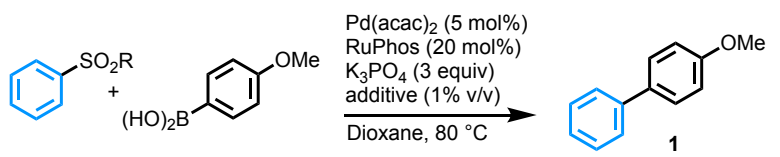

$\begin{array}{lllr}\text { entry } & \mathrm{R} & \text { additive } & \text { Yield } 1(\%)^{a} \\ 1 & \mathrm{Ph} & \text { DMSO } & 14^{b} \\ 2 & \mathrm{CH}_{3} & \text { DMSO } & <1 \\ 3 & \mathrm{CH}_{2} \mathrm{~F} & \mathrm{DMSO} & <1 \\ 4 & \mathrm{CHF}_{2} & \mathrm{DMSO} & <1 \\ 5 & \mathrm{CF}_{3} & \mathrm{DMSO} & 95 \\ 6 & \mathrm{CF}_{3} & - & 55 \\ 7 & \mathrm{CF}_{3} & \mathrm{H}_{2} \mathrm{O}^{c} & 38 \\ 8 & \mathrm{CF}_{3} & \mathrm{HMPA} & 77 \\ 9 & \mathrm{CF}_{3} & (\mathrm{PhSOCH})_{2}{ }^{d} & 5 \\ 10 & \mathrm{CF}_{3} & - & <1^{e} \\ 11 & \mathrm{CF}_{3} & - & 90^{f} \\ 12 & 3,5-\text { bis }\left(\mathrm{CF}_{3}\right) \mathrm{Ph} & \mathrm{DMSO} & <1\end{array}$

alsolated yield. ${ }^{b} 130{ }^{\circ} \mathrm{C} .{ }^{c} 0.2 \%(\mathrm{v} / \mathrm{v}) .{ }^{d} 50 \mathrm{~mol} \%$. ${ }^{e} \mathrm{DMSO}$ as a solvent. ${ }_{2} \%$ (w/w) Tocopherol methoxypolyethylene glycol succinate solution in water as a solvent. acac $=$ acetylacetone; DMSO = dimethyl sulfoxide; HMPA = hexamethylphosphoramide; RuPhos $=2$ dicyclohexylphosphino-2',6'-diisopropoxybiphenyl.

a)<smiles>O=S(=O)([18F])c1ccccc1</smiles><smiles>Cc1ccc(Cl)cc1</smiles>
$\underset{2{ }^{\circ} \mathrm{C}}{\stackrel{\mathrm{Ar}-\mathrm{B}(\mathrm{OH})_{2}}{\longrightarrow}}$
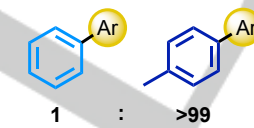

b)<smiles>Cc1ccc([N+](=O)[O-])cc1</smiles>
$\mathrm{Ar}-\mathrm{B}(\mathrm{OH})_{2}$
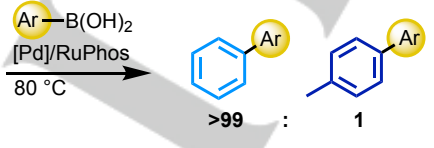

c)

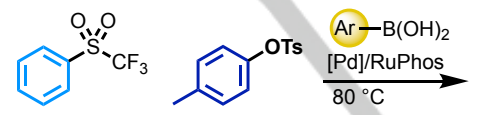

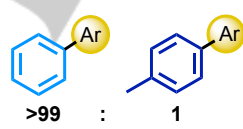

Scheme 2. Competition studies of sulfonyl arene versus: a) chloroarene, reaction conditions: $\mathrm{Pd}(\mathrm{OAc})_{2}(1 \mathrm{~mol} \%)$, XPhos ( $3 \mathrm{~mol} \%$ ), $\mathrm{K}_{3} \mathrm{PO}_{4}$ ( 3 equiv), THF, $22^{\circ} \mathrm{C}, 17 \mathrm{~h}$; b) nitroarene or $\mathrm{c}$ ) aryl tosylate, reaction conditions: $\mathrm{Pd}(\mathrm{acac})_{2}(5 \mathrm{~mol} \%)$, RuPhos (20 mol\%), $\mathrm{K}_{3} \mathrm{PO}_{4}$ (3 equiv), dioxane, $80{ }^{\circ} \mathrm{C}, 17 \mathrm{~h} . \quad$ BrettPhos $=2-$ (dicyclohexylphosphino)3,6-dimethoxy-2',4',6'-triisopropyl-1,1'biphenyl; THF = tetrahydrofuran; XPhos = 2-dicyclohexylphosphino2',4',6'-triisopropylbiphenyl.
The optimized conditions were then applied to a variety of aryl $\mathrm{CF}_{3}$ sulfones and aryl boronic acids (Table 2). Electron donating or withdrawing groups were well-tolerated on the boronic acid or on the sulfone. Coupling was selective for sulfone moieties over nitro groups $(\mathbf{3}, \mathbf{1 1}, \mathbf{2 3 - 2 5}, \mathbf{3 1})$, which opens the possibility

\section{Table 2. Substrate scope}

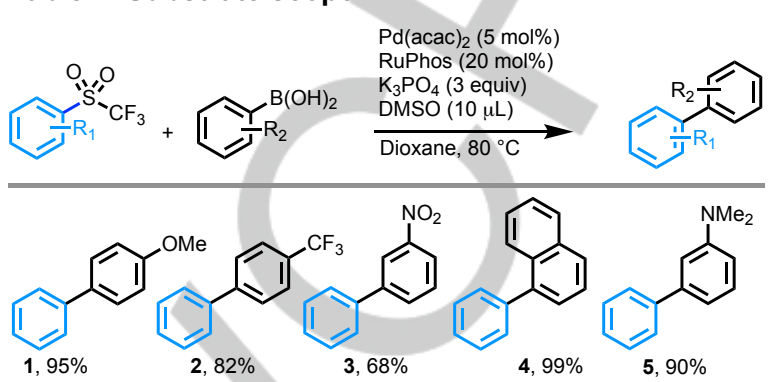

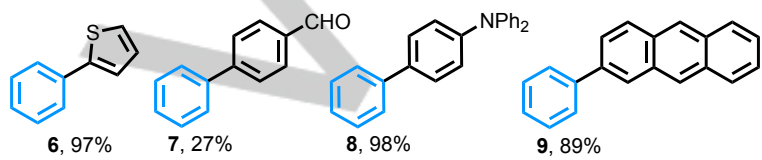<smiles>N#Cc1cccc(-c2cccc(-c3cccc([N+](=O)[O-])c3)c2)c1</smiles>

$10,93 \%$<smiles>COc1ccc(-c2ccc(C(=O)Nc3ccc(C(F)(F)F)cc3)cc2)cc1</smiles><smiles>COc1ccc(-c2ccccc2-c2ccccc2-c2ccc(C)c([18OH])c2)cc1</smiles><smiles>CN(C)c1cccc(-c2cccc(N=[N+]([O-])[O-])c2)c1</smiles>
22, $60 \%$ 23, $78 \%$ 24, $68 \%$ 25, $54 \%$<smiles></smiles><smiles>COc1ccc(-c2ccc(-c3ccc(-c4ccc(OC)cc4)c(N)c3)c(N=O)c2)cc1</smiles>
30, $86 \%$ $31,73 \%$

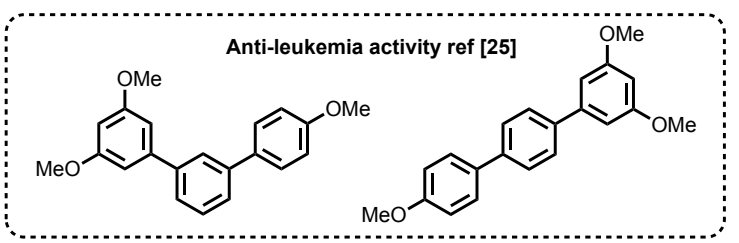


for sequential cross-coupling employing the recently disclosed nitro SMC reaction. ${ }^{[12]}$ Bulky boronic acids underwent crosscoupling in excellent yields (8-10, 17, 21 and 29). Thiophene boronic acids were also well-tolerated (6 and 13) although pyridine boronic acids did not react. 2-Fluoroaryl substitution on the sulfone partner did not impair reactivity $(20,22,23)$. 2-Pyridyl sulfones (26-29) and meta- and para- substituted biaryl sulfones underwent cross-coupling in good yields to afford $\mathbf{3 0}$ and $\mathbf{3 1}$, the latter two of which are analogs of anti-leukemia compounds. ${ }^{\text {[22] }}$ The main limitation of the scope occurs in the case of boronic acids bearing aldehyde groups, where cross-coupling occurred in lower yields in some cases (7, 12 and 22).

Taking advantage of the very different conditions required for cross-coupling of aryl chlorides $\left(22^{\circ} \mathrm{C}\right.$, using XPhos as ligand), aryl sulfones $\left(80^{\circ} \mathrm{C}\right.$, using RuPhos as ligand) and nitroarenes $\left(130^{\circ} \mathrm{C}\right.$, using BrettPhos as ligand), we developed a sequential SMC protocol for the synthesis of non-symmetric terphenyls and quaterphenyls (Scheme 3). SMC of the chloro group of a 2-chloro phenylsulfone with 3-nitrophenylboronic acid gave biphenyl 1a, followed by SMC of the sulfone group with 4-N-carbazolephenylboronic acid to give terphenyl $\mathbf{1 b}$, before a final SMC of the nitro group to afford quaterphenyl 1c. Chloro, sulfone and nitro leaving groups can be differentiated on the same aryl ring, as evidenced by a chloro-selective SMC of 1-chloro-2-nitro-4((trifluoromethyl)-sulfonyl)benzene to give biphenyl 2a, followed by a sulfone-selective SMC to give $\mathbf{2 b}$. Compounds $\mathbf{3 0}$ and $\mathbf{3 1}$ were prepared in an analogous fashion, described in the SI.
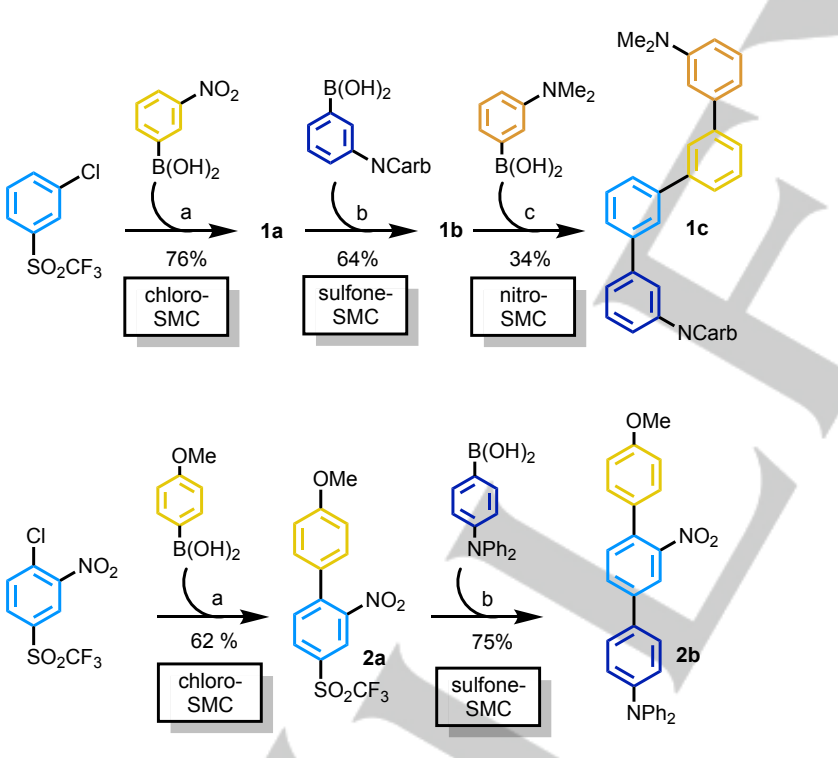

Scheme 3. Synthesis of non-symmetric terphenyls and quaterphenyls by taking advantage of the relative SMC reactivity: chloroarenes > sulfonylarene > nitroarenes. a: $\mathrm{Pd}(\mathrm{OAc})_{2}(1 \mathrm{~mol} \%)$, XPhos (3 mol\%), $\mathrm{K}_{3} \mathrm{PO}_{4}$ (3 equiv), THF, $22{ }^{\circ} \mathrm{C}, 17 \mathrm{~h}$; b: standard conditions; c: $\mathrm{Pd}(\mathrm{acac})_{2}$ (5 mol\%), BrettPhos (20 mol\%), 18 crown-6 (10 mol\%), $\mathrm{K}_{3} \mathrm{PO}_{4}$ (3 equiv), dioxane, $130{ }^{\circ} \mathrm{C}, 48 \mathrm{~h}$. $\mathrm{NCarb}=\mathrm{N}$-carbazole.

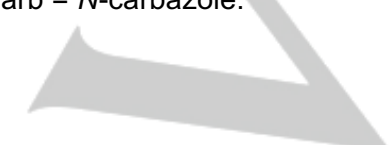

To gain insight into the mechanism, a stoichiometric reaction between (1,5-cyclooctadiene)bis(trimethylsilylmethyl)palladium, a $\mathrm{Pd}(0)$ precursor, and $\mathrm{PhSO}_{2} \mathrm{CF}_{3}$ in the presence of RuPhos was undertaken to isolate the reaction intermediate $\mathbf{X} \mathbf{1}$ (eq 1).

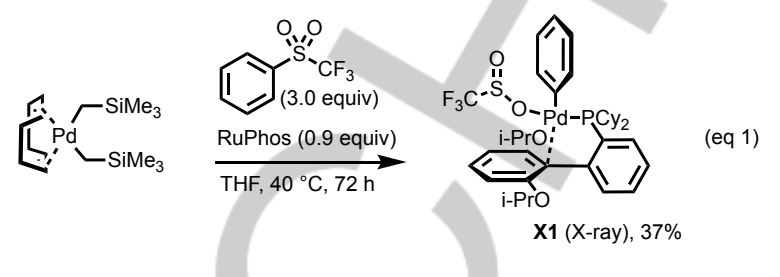

The X-ray crystal structure of $\mathbf{X} 1$ revealed that after oxidative addition, the palladium is bound to the oxygen of the sulfinate, suggesting that the palladium complex rearranges, after oxidative addition into the $\mathrm{C}-\mathrm{S}$ bond, to minimize dipole interactions in the apolar solvent used for crystallization. ${ }^{[38]}$ The structure is otherwise similar to what has been observed for oxidative addition to arylhalides ${ }^{[39]}$ and nitroarenes, ${ }^{[12]}$ with the palladium in a square planar geometry. A stoichiometric reaction between $\mathbf{X} 1$ and 4-methoxyphenylboronic acid at $25^{\circ} \mathrm{C}$, but under otherwise standard conditions, afforded biaryl $\mathbf{1}$ in nearly quantitative yield, suggesting that oxidative addition is the turnover-limiting step in the catalytic cycle. Using $\mathbf{X} 1$ (5 mol\%) to couple 4-methoxyphenylboronic acid and $\mathrm{PhSO}_{2} \mathrm{CF}_{3}$ under otherwise standard conditions afforded 1 in $62 \%$ yield, whereas the presence of excess RuPhos (20 mol\%) increased the yield to $95 \%$, suggesting the beneficial effect of excess RuPhos stems from its ability to delay catalyst decomposition. To track the fate of the leaving group, a typical crude reaction mixture (specifically, that described in Table 1, entry 5) was extracted with $\mathrm{D}_{2} \mathrm{O}$, revealing the presence of trifluoromethanesulfinate as the only compound visible by ${ }^{19} \mathrm{~F}$ NMR. Therefore, although oxidative addition into sulfonyl chlorides is known to release $\mathrm{SO}_{2}$ and chloride, here the leaving group remains intact as a trifluoromethanesulfinate. ${ }^{[18]}$

DFT calculations were undertaken to further probe the reaction mechanism and complement our experimental observations. Since the experiments described above support oxidative addition as being turnover-limiting, as might be expected in an SMC reaction with a challenging electrophile, ${ }^{2}$ the Gibbs energy profiles for the insertion of the catalyst into the $\mathrm{C}-\mathrm{S}$ bonds of $\mathrm{PhSO}_{2} \mathrm{Ph}$ and $\mathrm{PhSO}_{2} \mathrm{CF}_{3}$ were calculated using B3LYPD3/def2-TZVP. The first step is the exchange of a coordinated solvent molecule (dioxane) for the substrate to form a $\pi$-complex and is slightly favored for $\mathrm{PhSO}_{2} \mathrm{CF}_{3}$ (Figure 1). The Gibbs energy of the transition state corresponding to oxidative addition into the $\mathrm{C}-\mathrm{S}$ bond has an activation energy for $\mathrm{PhSO}_{2} \mathrm{Ph}$ that is 5.8 $\mathrm{kcal} / \mathrm{mol}$ higher than for $\mathrm{PhSO}_{2} \mathrm{CF}_{3}$, consistent with the observed experimental trend for the overall catalytic reaction and coinciding with the increased polarization of the $\mathrm{C}-\mathrm{S}$ bond in the latter case. The $S$-bound $\mathrm{Pd}$ intermediate is close in energy to the observed O-bound XRD structure $\mathbf{X} 1$. The full computational details, structures, and a rendering of the transition state structure are included in Supporting Information. 


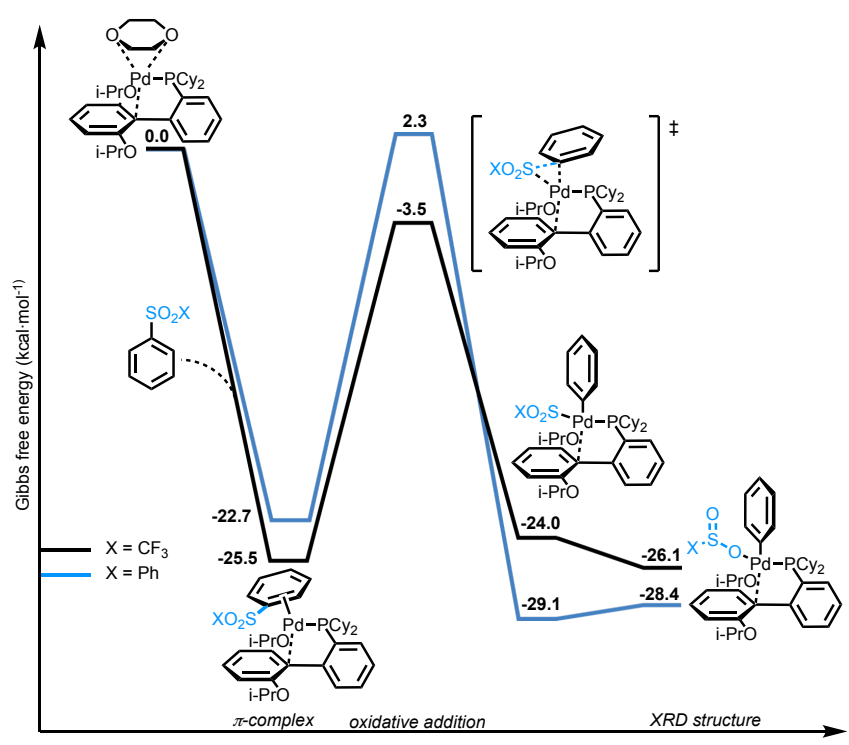

Figure 1. Calculated Gibbs energies for the oxidative addition of sulfones to $\mathrm{Pd}(0)-\mathrm{RuPhos}(\mathrm{kcal} / \mathrm{mol})$.

In summary, we have described the Suzuki-Miyaura crosscoupling of aryl sulfones, which involves a relatively rare oxidative addition of palladium into the aryl sulfone $\mathrm{C}-\mathrm{S}$ bond. Most notably, trifluoromethylsulfones display an intermediate level of crosscoupling reactivity between that of nitroarenes and aryl halides, enabling the facile synthesis of non-symmetric ter- and quaterphenyl motifs via sequential cross-coupling. We anticipate that the deliberate development of electrophilic partners with complementary reactivity in other cross-coupling reactions will further streamline approaches to iterative synthesis.

\section{Acknowledgements}

J.M. thanks the European Research Council (ERC) (grant agreement $n^{\circ}$ 639170) and ANR LabEx "Chemistry of Complex Systems" (ANR-10-LABX-0026 CSC). A.S. thanks the EU for a H2020 Marie Skłodowska Curie Fellowship (792101). P.C. thanks the French government for an MRT fellowship. CNR thanks NSERC of Canada for funding through the Discovery Grants program (application 418505-2012) and Compute Canada for supercomputing resources.

\section{Notes}

The authors declare no competing financial interest.

[1] A. Suzuki, Angew. Chem. Int. Ed. 2011, 50, 6722-6737.

[2] A. F. Littke, C. Dai, G. C. Fu, J. Am. Chem. Soc. 2000, 122, 4020-4028.

[3] S. A. Kazi, E. M. Campi, M. T. W. Hearn, Tetrahedron 2018, 74, 1731-1741.

[4] K. Kawada, A. Arimura, T. Tsuri, M. Fuji, T. Komurasaki, S. Yonezawa, A. Kugimiya, N. Haga, S. Mitsumori, M. Inagaki, et al., Angew. Chem. Int. Ed. 1998, 37, 973-975.
[5] S. T. Keaveney, G. Kundu, F. Schoenebeck, Angew. Chem Int. Ed. 2018, 57, 12573-12577.

[6] I. Kalvet, G. Magnin, F. Schoenebeck, Angew. Chem. Int. Ed. 2017, 56, 1581-1585.

[7] X. Li, C. Liu, L. Wang, Q. Ye, X. Jin, Z. Jin, Org. Biomol. Chem. 2018, 16, 8719-8723.

[8] P. Dobrounig, M. Trobe, R. Breinbauer, Monatsh. Chem. 2017, 148, 3-35.

[9] J. Almond-Thynne, D. C. Blakemore, D. C. Pryde, A. C. Spivey, Chem. Sci. 2017, 8, 40-62.

[10] C. Wang, F. Glorius, Angew. Chem. Int. Ed. 2009, 48, 52405244.

[11] R. Rossi, F. Bellina, M. Lessi, Adv. Synth. Catal. 2012, 354 $1181-1255$.

[12] M. R. Yadav, M. Nagaoka, M. Kashihara, R.-L. Zhong, T. Miyazaki, S. Sakaki, Y. Nakao, J. Am. Chem. Soc. 2017, 139 9423-9426.

[13] Z.-C. Cao, S.-J. Xie, H. Fang, Z.-J. Shi, J. Am. Chem. Soc. 2018, 140, 13575-13579.

[14] A. M. Norberg, L. Sanchez, R. E. Maleczka, Curr. Opin. Drug Discov. Devel. 2008, 11, 853-869.

[15] K. Muto, J. Yamaguchi, D. G. Musaev, K. Itami, Nat. Commun. 2015, 6, DOI 10.1038/ncomms8508.

[16] D.-G. Yu, Z.-J. Shi, Angew. Chem. Int. Ed. 2011, 50, 70977100

[17] T. Schaub, M. Backes, U. Radius, J. Am. Chem. Soc. 2006, 128, 15964-15965.

[18] S. R. Dubbaka, P. Vogel, Org. Lett. 2004, 6, 95-98.

[19] S. B. Blakey, D. W. C. MacMillan, J. Am. Chem. Soc. 2003, $125,6046-6047$

[20] M. Tobisu, T. Shimasaki, N. Chatani,Angew. Chem. Int. Ed. 2008, 47, 4866-4869.

[21] L. S. Liebeskind, J. Srogl, Org. Lett. 2002, 4, 979-981.

[22] R. Martin, S. L. Buchwald, Acc. Chem. Res. 2008, 41, 14611473.

[23] E. C. Garnier-Amblard, L. S. Liebeskind, in Boronic Acids (Ed.: D.G. Hall), Wiley-VCH Verlag GmbH \& Co. KGaA, Weinheim, Germany, 2011, pp. 363-391.

[24] J.-K. Liu, Chem. Rev. 2006, 106, 2209-2223.

[25] M. Roberti, D. Pizzirani, M. Recanatini, D. Simoni, S. Grimaudo, Di Cristina, V. Abbadessa, N. Gebbia, M. Tolomeo, J. Med. Chem. 2006, 49, 3012-3018.

[26] J. Clayden, M. Julia, J. Chem. Soc. Chem. Commun. 1993 1682.

[27] Y. Sumii, M. Taniguchi, X.-H. Xu, E. Tokunaga, N. Shibata, Tetrahedron 2018, 74, 5635-5641.

[28] S. Okumura, Y. Nakao, Org. Lett. 2017, 19, 584-587.

[29] G. A. Olah, A. Orlinkov, A. B. Oxyzoglou, G. K. S. Prakash, J. Org. Chem. 1995, 60, 7348-7350.

[30] R. R. Merchant, J. T. Edwards, T. Qin, M. M. Kruszyk, C. Bi, G. Che, D.-H. Bao, W. Qiao, L. Sun, M. R. Collins, et al., Science 2018, 360, 75-80.

[31] S. E. Denmark, A. J. Cresswell, J. Org. Chem. 2013, 78, 12593-12628.

[32] M. Nambo, E. C. Keske, J. P. G. Rygus, J. C.-H. Yim, C. M. Crudden, ACS Catal. 2017, 7, 1108-1112.

[33] Z. T. Ariki, Y. Maekawa, M. Nambo, C. M. Crudden, J. Am. Chem. Soc. 2018, 140, 78-81.

[34] L. Gong, H. Sun, L.-F. Deng, X. Zhang, J. Liu, S. Yang, D. Niu, J. Am. Chem. Soc. 2019, jacs.9b02312.

[35] E. J. Hennessy, M. Cornebise, L. Gingipalli, T. Grebe, S. Hande, V. Hoesch, H. Huynh, S. Throner, J. Varnes, Y. Wu, Tetrahedron Lett. 2017, 58, 1709-1713.

[36] S. Handa, Y. Wang, F. Gallou, B. H. Lipshutz, Science 2015, 349, 1087-1091.

[37] S. Handa, J. C. Fennewald, B. H. Lipshutz, Angew. Chem. Int. Ed. 2014, 53, 3432-3435.

[38] CCDC Number: 1948443 DOI 10.5517/ccdc.csd.cc23dj02.

[39] B. P. Fors, S. L. Buchwald, J. Am. Chem. Soc. 2009, 131, 12898-12899. 
Keywords: Aryl sulfones; Suzuki-Miyaura Coupling; palladium catalysis; teraryl; quaterphenyl.

Entry for the Table of Contents:

\section{COMMUNICATION}

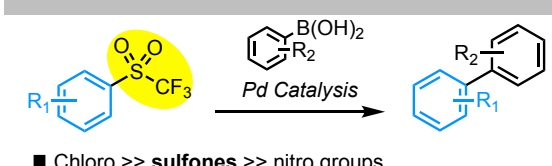

- Chloro >> sulfones $>>$ nitro groups

- Rapid access to non-symmetric ter-and quaterphenyls

Aryl sulfones undergo Suzuki-Miyaura coupling with intermediate reactivity between aryl halides and nitroarenes, enabling the iterative synthesis of non-symmetric polyaromatics.
Paul Chatelain, Abhijit Sau, Christopher N. Rowley, Joseph Moran*

Page No. - Page No.

Suzuki-Miyaura Coupling of (Hetero)Aryl Sulfones:

Complementary Reactivity Enables Iterative Polyaryl Synthesis 